\section{Battery Charger Design for the Columbus MTFF Power System}

\section{E. VAN DIJK}

\section{J. B. KLAASSENS}

Delft University of Technology

H. J. N. SPRUIJT

D. M. O'SULLIVAN

European Space Agency

A novel pulsewidth-modulated (PWM) dc-dc converter topology is proposed for the battery charge regulator (BCR) of the Columbus Man-Tended Free-Flyer (MTFF) power system. The system is a regulated bus system. Bus voltage control is implemented at the input of the BCR. The use of a conventional buck topology with PWM conductance control at the input results in a second-order behavior. A study of new PWM dc-dc converter topologies has been made to attain a suitable topology. The proposed converter topology is designed and a breadboard including the control loop has been built and tested. The experimental results show that the converter operates according to the design constraints.

\section{INTRODUCTION}

The Columbus Man-Tended Free-Flyer (MTFF) laboratory is a part of the Columbus project of the European Space Agency (ESA). It is mainly an automated, self-contained space station, consisting of two parts.

The resource module will carry all resources and services necessary for its operation, such as power, communications, attitude control, and electrical support systems. The pressurized module will provide the laboratory facility for the material and life science experiments. The Free-Flyer will be able to dock to either the International Space Station or the spacecraft Hermes. Astronauts will then be able to enter the spacecraft and work in the pressurized module.

Since the MTFF will be an autonomous spacecraft, it needs to have an independent power system. A schematic overview of the power system of the Free-Flyer is shown in Fig. 1. Three different sources of power are available: the solar arrays, the nickel-hydrogen batteries, and power supplied via the external input of the system. The energy is distributed to the payloads via a regulated bus. For large systems with many payloads as in the case of the MTFF system, the regulated bus systems is the preferred approach.

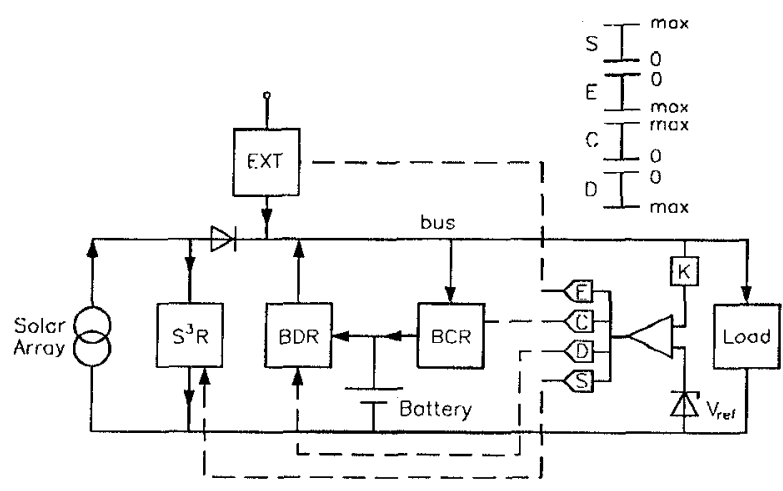

Fig. 1. Power System of the Columbus MTFF.

The method of regulating the power flow from the different energy sources is identified as domain control. There are four domains of regulation: (S)hunt, (C)harge, (D)ischarge and (E)xternal power source domain. The main bus voltage of the system is sequentially controlled in one domain at a time. The control system compares the bus voltage to a reference voltage and the resulting error signal determines in which domain the power system will be operating. More information on the power system is found in [1-3].

In the (C)harge domain, the charging of the batteries is controlled depending on the amount of power available from the solar array or an external power source. The battery charge regulator (BCR) 


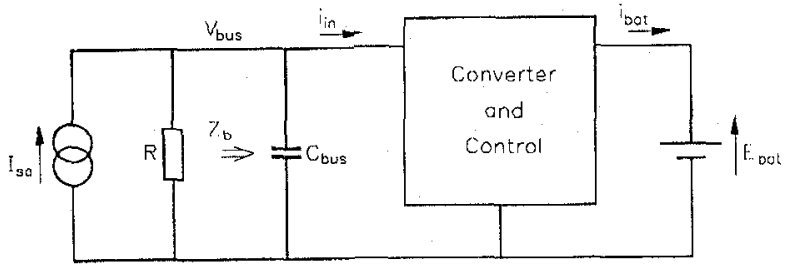

Fig. 2. Simplified system for analysis of BCR application.

directly controls the main bus voltage and at the same time charges the batteries with the surplus of electrical energy available from the solar arrays. The unusual feature of this BCR application is that the bus voltage control has to be applied at what would normally be considered the input port of the regulator.

All four controllers of the various domains regulate the bus voltage by controlling their current. The current is set by the error voltage from the error amplifier. This means that the controllers have a specific conductance. The conductances for the different controllers are made identical to simplify the stabilization of the four different control loops. The same error amplifier can be used for all four controllers.

The preferred method for controlling power regulators used in modern space power systems is pulsewidth modulated (PWM) Conductance Control [4]. This method allows a simple first-order control, perfect current sharing of parallel converters and provides inherent overload protection. To achieve the input conductance control for this application, current sensing is applied to the input port. With proper design of the current loop, the regulator acts like a voltage-controlled current sink, resulting in a first-order control of the bus voltage.

\section{SPECIFIC REQUIREMENTS FOR THE BCR}

The BCR of the MTFF power system consists of twelve units connected in parallel. These units are converters with their control loops to convert power from the main bus to the batteries. For the analysis it is not necessary to consider the twelve units in parallel. The BCR application is simplified by reducing it to one unit. This means that the solar array current, load, and bus capacitor are also scaled down. The system of one BCR unit is illustrated in Fig. 2.

The specific requirements for one BCR unit are presented in Table $\mathbb{I}$. These values are presented and explained in [5]. Some of the requirements are standardized by ESA and can be found in [6].

The impedance $Z_{b}$ of the voltage-regulated bus shall be below the impedance mask as presented in Fig. 3. The maximum impedance is calculated from the constraint that there shall be $1 \%$ ac bus voltage
TABLE I

Specific Requirements

\begin{tabular}{|c|c|}
\hline Solar ar'cy current $\left(I_{S A}\right)$ & $145 \mathrm{~A}$ \\
\hline Nominal power $\left(P_{n}\right)$ & $900 \mathrm{~W}$ \\
\hline Nominal bus voltage $\left(V_{\text {bus }}\right)$ & $120 \mathrm{~V}$ \\
\hline Nominal input curent $\left(\mathrm{l}_{n}\right)$ & $7.5 \mathrm{~A}$ \\
\hline Nom nal load resistonce (?) & $17.1 s$ \\
\hline Minimum bottery voltage $\left(E_{\text {rot.min }}\right)$ & $33 \vee$ \\
\hline Maximum battery voltage $\left(\mathrm{E}_{\text {batmax }}\right)$ & $105 \mathrm{~V}$ \\
\hline Maximum battery current (l bat.mox $_{\text {ba }}$ ) & $15 \mathrm{~A}$ \\
\hline Maximum battery current rlpple ( $\left.\Delta\right|_{\text {bat.max }}$ ) & $1.5 \wedge$ \\
\hline Required conductance $(S)$ & $2.5 \mathrm{~s}$ \\
\hline Switching frequency $\left(f_{3}\right)$ & $100 \mathrm{kHz}$ \\
\hline Minimun efficiency & $92 \%$ \\
\hline Bus stability: minimum phase marg $\quad$ n & $50^{\circ}$ \\
\hline minimum gain morgin & $10 \leqslant 3 B$ \\
\hline Maximum bus ripple volnge & $0.6 \mathrm{~V}$ \\
\hline Maximum bus spike voltage & $2.4 \mathrm{~V}$ \\
\hline Maximum bus impedance ( $\left(\mathrm{v}_{\mathrm{b}} \mathrm{mox}\right)$ & $320 \mathrm{~m} \Omega$ \\
\hline Minimum bus capacitar & $50 \mu \mathrm{F}$ \\
\hline Maximum $A C$ bus voltage variations of $50 \%$ current modulation & $1.2 \mathrm{~V}$ \\
\hline
\end{tabular}

Note: Roman symbols here correspond to italic symbols in text.

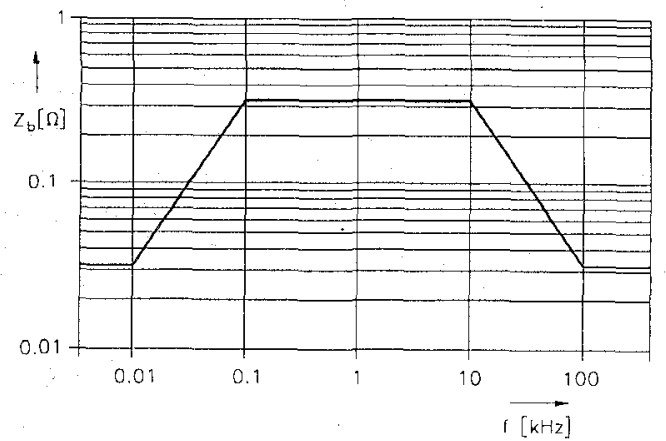

Fig. 3. Bus impedance mask

TABLE II

Regions of Bus Impedance Mask

\begin{tabular}{|l|l|}
\hline $\begin{array}{l}0.1 \mathrm{kHz} \text { to } 10 \mathrm{kHz} \\
10 \mathrm{~Hz} \text { to } 100 \mathrm{~Hz} \\
10 \mathrm{kHz} \text { to } 100 \mathrm{kHz} \\
<10 \mathrm{~Hz} \\
>100 \mathrm{kHz}\end{array}$ & $\begin{array}{l}Z_{\mathrm{b} \text { max }} \\
\text { effect of integral feedback } \\
\text { experience and effect of bus capacitor }\end{array}$ \\
$0.1 \mathrm{Z}_{\mathrm{b} . \text { max }}$ due to residual resistance
\end{tabular}

variation due to $50 \%$ current modulation:

$$
Z_{b, \max }=\frac{0.01 V_{\text {bus }}^{V_{\text {bus }}}}{0.5 P_{n} / V_{\text {bus }}}=0.02 \frac{V_{\text {bus }}^{2}}{P_{n}}=320 \mathrm{~m} \Omega .
$$

The frequency range of the bus impedance mask is presented in Table II. The minimum required value for the bus capacitor is

$$
C_{b, \min }=\frac{1}{2 \pi 10^{4} Z_{b, \max }}=50 \mu \mathrm{F}
$$




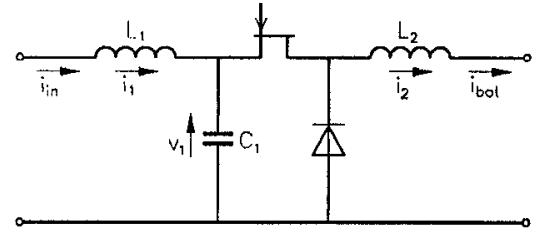

Fig. 4. Buck converter with input filter.

\section{A NOVEL TOPOLOGY FOR THE BCR}

Because the battery voltage is always lower than the bus voltage in this application, a step-down converter must be employed. As input current sensing will be applied to regulate the input current, the input current must be continuous. This suggests the use of a conventional buck converter with an input filter as shown in Fig. 4.

In the next section it will be demonstrated that the small-signal transfer function $H(s)$ of the duty ratio to the input current $i_{\text {in }}$ of the applied converter determines the behavior of the control loop (see (10)). It is discussed there that this function should behave as a first-order function for high frequencies, to realize a stable PWM conductance control loop.

The input current $i_{\text {in }}$ of the buck converter with input filter flows through the input filter inductor resulting in a second-order behavior of the small-signal transfer function $H(s)$ of the duty ratio $d$ to the input current $i_{\text {in }}$ for high frequencies. When applying the buck converter with input filter of Fig. 4 in the BCR application of Fig. 2, this function is found as:

$$
\begin{array}{r}
H(s)=\frac{I_{2}\left(\frac{L_{2}}{R} s+L_{2} C_{b} s^{2}\right)+D V_{1}\left(\frac{1}{R}+C_{b} s\right)}{D^{2}+\frac{D^{2} L_{1}+L_{2}}{R} s+\left(D^{2} L_{1}+L_{2}\right) C_{b} s^{2}} \\
+C_{1} L_{2} s^{2}+\frac{L_{1} L_{2} C_{1}}{R} s^{3}+L_{1} L_{2} C_{1} C_{b} s^{4}
\end{array}
$$

where $s$ is the Laplace operator and $D, V_{1}, I_{1}$, and $I_{2}$ are the steady state values of the duty ratio $d$, the voltage $v_{1}$ across capacitor $C_{1}$ and the currents $i_{1}$ and $i_{2}$ through the inductors $L_{1}$ and $L_{2}$, respectively. This function behaves as a second-order function for high frequencies:

$$
H(s \rightarrow \infty)=\frac{I_{2}}{L_{1} C_{1} s^{2}} .
$$

This means that the buck converter with input filter cannot be used for this application. The second-order behavior of this function will result in an unstable operation of the PWM conductance control loop (see next section).

A study was performed on the use of new converter topologies for the BCR application [5]. The study proposes to use the novel topology depicted in Fig. 5. The topology of Fig. 5 is similar to the buck converter

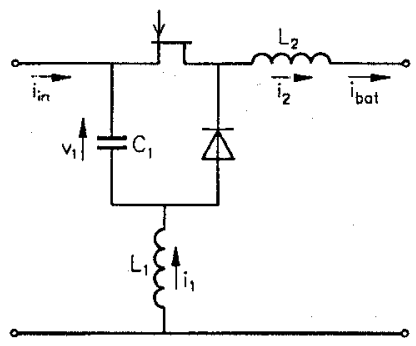

Fig. 5. Novel topology for BCR application.

with input filter, where the input filter inductor $L_{1}$ has been relocated to the return line. This topology has been mentioned in the classifications of topologies in $[7,8]$. According to $[7,8]$, the steady state behavior of this topology is the same as that of the buck converter with input filter.

The small-signal transfer function $H(s)$ of the duty ratio $d$ to the input current $i_{\text {in }}$ for this topology in the BCR application is found as

$$
\begin{gathered}
\frac{D^{\prime} L_{1}+L_{2}}{R} s+\left[\left(D^{\prime} L_{1}+L_{2}\right) C_{b} s^{2}\right] I_{2} \\
H(s)=\frac{+\left[\left(\frac{1}{R}+C_{b} s\right) D+\frac{L_{1} C_{1}}{R} s^{2}+L_{1} C_{1} C_{b} s^{3}\right] V_{1}}{D^{2}+\frac{D^{\prime 2} L_{1}+L_{2}}{R} s+\left(D^{\prime 2} L_{1}+L_{2}\right) C_{b} s^{2}+} \\
\left(L_{1}+L_{2}\right) C_{1} s^{2}+\frac{L_{1} L_{2} C_{1}}{R} s^{3}+L_{1} L_{2} C_{1} C_{b} s^{4}
\end{gathered}
$$

where $D^{\prime}=1-D$. This function behaves as a first-order function for high frequencies:

$$
H(s \rightarrow \infty)=\frac{V_{1}}{L_{2} s} .
$$

The influence of the second-order input filter on the small-signal transfer function $H(s)$ of the duty ratio $d$ to the input current $i_{\text {in }}$ is now completely avoided for high frequencies.

Capacitor $C_{1}$ is calculated such that the voltage ripple $\Delta V_{1}$ across the capacitor is not more than $1 \%$ of the maximum voltage across it. The voltage $V_{1}$ across capacitor $C_{1}$ equals the bus voltage $V_{\text {bus. }}$. This gives

$$
\begin{aligned}
C_{1} & =\frac{I_{\text {bat,max }}}{f_{S} \Delta V_{1, \text { max }}} D_{\min }\left(1-D_{\text {min }}\right) \\
& =\frac{15}{10010^{3} 1.2} 0.525(1-0.525)=31 \mu \mathrm{F}
\end{aligned}
$$

where $D_{\min }$ is the minimum duty ratio for the steady state operation:

$$
D_{\min }=\frac{E_{\text {bat, } \min }}{V_{\text {bus }}}=\frac{63}{120}=0.525 .
$$

Inductor $L_{2}$ is calculated such that the battery current ripple does not exceed the maximum value presented 


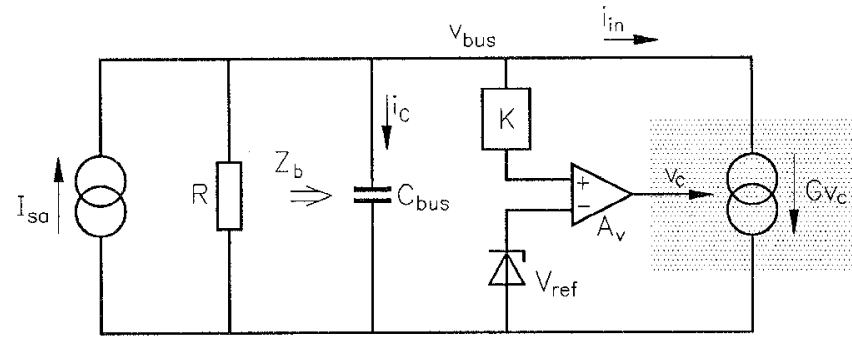

Fig. 6. PWM conductance control for BCR application.

in Table I. This gives

$$
\begin{aligned}
L_{2} & =\frac{V_{\text {bus }}}{f_{S} \Delta I_{\text {bat, } \max }} D_{\min }\left(1-D_{\min }\right) \\
& =\frac{120}{10010^{3} 1.5} 0.525(1-0.525) \\
& =200 \mu \mathrm{H} .
\end{aligned}
$$

The input filter inductor $L_{1}$ is determined at the end of the next section.

\section{PWM CONDUCTANCE CONTROL FOR THE BCR}

PWM conductance control is used by ESA in its space programs for PWM-type regulators [4]. This method is a conventional PWM modulation technique based on the averaged value of the current. The advantages compared with other techniques are its relatively simple design, the noncriticality of components, and the simple conversion to integrated-circuit technology.

The general concept of PWM conductance control is a voltage-controlled current sink which is used to control a desired output function. For the BCR application shown in Fig. 2, the desired output function is the bus voltage $v_{\text {bus }}$ as shown in Fig. 6 . The unusual feature of this type of control in the BCR application is that what would normally be considered the input port of the regulator is being controlled while the output is supplying energy to the batteries.

The BCR acts as a voltage-controlled current sink with a conductance $G$. The input current $i_{\text {in }}$ of the $\mathrm{BCR}$ is adjusted by the control voltage $v_{c}$. This is established by a simple voltage feedback loop. The bus voltage is compared with a reference voltage $V_{\text {ref }}$ via a voltage divider $K$. The resulting error signal multiplied by a gain $A_{v}$ is then employed to adjust the controlled current sink. Thus, the bus voltage is regulated by controlling the current drawn from the bus by the BCR.

This type of control is a first-order control which is very uncomplicated and stable. Another benefit is the ability to employ parallel power stages. The BCR units have the same transconductance and the same control voltage and thus have the same input current. Current

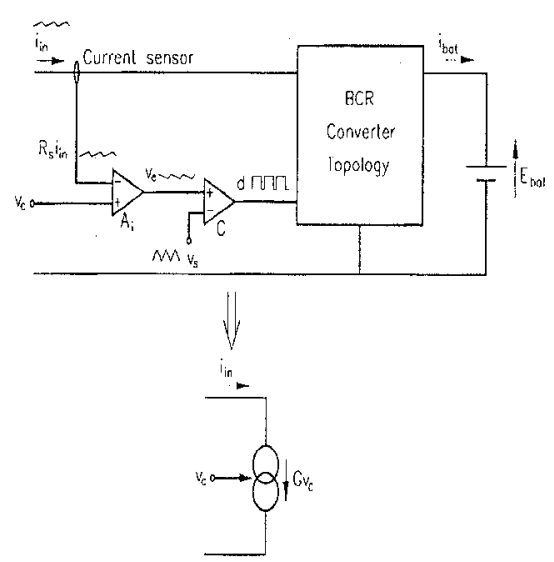

Fig. 7. Current loop for PWM conductance control.

sharing is ensured. Another advantage is the system overload protection as a result of the inherent current limitation.

\section{Current Loop}

The control loop to convert the BCR converter topology into a controlled current sink is shown in Fig. 7. The input current $i_{\text {in }}$ is measured with a current sensor having a characteristic $R_{s}$. The output voltage of the current sensor $R_{s} i_{\mathrm{in}}$ is subtracted from the control voltage $v_{c}$ and multiplied by a constant amplification $A_{i}$. The resulting error signal $v_{e}$ is compared with a sawtooth voltage $v_{s}$. The comparator $C$ provides the duty ratio modulation signal $d$ which drives the active switch of the BCR converter.

The loop gain $T_{i}$ of the current loop can be found as

$$
T_{i}(s)=\frac{R_{s} A_{i}}{V_{s}} H(s)
$$

The function $H(s)$ is the small-signal transfer function of the duty ratio to the input current of the converter, as discussed in the previous section. It is clear that this function depends on the topology used for the BCR. $V_{s}$ is the peak-to-peak value of the sawtooth voltage.

The transconductance $G_{i}$ of the current loop is given by

$$
G_{i}(s)=\frac{i_{\text {in }}}{v_{c}}=\frac{T_{i}(s)}{R_{s}\left(1+T_{i}(s)\right)}=\frac{G}{1+\frac{1}{T_{i}(s)}}
$$

where

$$
G=\frac{1}{R_{s}}
$$

is the conductance of the regulator. Equation (11) shows that for a large loop gain $T_{i}$, the transconductance $G_{i}$ equals the conductance $G$ while for a small loop gain the transconductance equals $G$ times the loop gain. The behavior of the loop gain is 


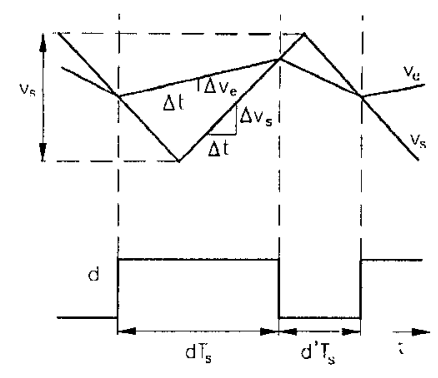

Fig. 8. Signals at inputs and output of comparator.

completely established by the transfer function $H(s)$. To obtain a stable current loop, this function should behave as a first-order system around the bandwidth of the transconductance. The best way to achieve this is to have a transfer function with $\mathbf{n}$ poles (the order of the converter) and $n-1$ zeros. The poles and zeros should be located at least one decade below the transconductance bandwidth. The function behaves then as a first-order function for frequencies around the bandwidth and higher, because of the extra pole. The result is a phase margin of almost $90^{\circ}$. As shown by (6), the transfer function $H(s)$ of the topology of Fig. 5 behaves as a first-order function for high frequencies. Applying this topology with the current loop as shown in Fig. 7, the transconductance $G_{i}(s)$ can be described as a first-order function. Thus the current loop modifies the 4th-order converter topology into a first-order current sink.

When the current amplifier gain $A_{i}$ is increased, the bandwidth of the current loop increases. However, the amplifier gain is limited and so is the bandwidth. This is due to the fact that the amplifier amplifies the current ripple, resulting in a ripple on the error voltage. Fig. 8 shows the error signal $v_{e}$ and the sawtooth voltage $v_{s}$ and the resulting duty ratio signal $d$. We can see in Fig. 8 that the slew rate of the error signal should not exceed the slew rate of the sawtooth, otherwise the intersection between both signals will be undefined, resulting in unstable operation.

The slew rate of the symmetrical sawtooth signal is

$$
\frac{\Delta v_{s}}{\Delta t}=2 f_{s} V_{s}
$$

The slew rate of the error voltage is

$$
\frac{\Delta v_{s}}{\Delta t}=R_{s} A_{i} \frac{\Delta i_{\mathrm{in}}}{\Delta t}
$$

where $\Delta i_{\text {in }} / \Delta t$ is the slew rate of the input current. Comparing (13) and (14) results in the maximum value for the current amplification:

$$
A_{i}=\frac{2 f_{s} V_{s}}{R_{s} \frac{\Delta \dot{i}_{\text {in }}}{\Delta t}}
$$

The maximum value is dependent on the worst case slew rate of the input current. In the case of a conventional ramped sawtooth its slew rate would be $f_{s} V_{s}$ resulting in a maximum amplification of half the one given by (15). The bandwidth of the current loop is then half of the bandwidth obtained with a symmetrical sawtooth.

The worst case current slope of the input current $i_{\text {in }}$ of the novel topology of Fig. 7 is found as

$$
\frac{\Delta i_{\text {in }}}{\Delta t}=\frac{\Delta i_{2}}{\Delta t}-\frac{\Delta i_{1}}{\Delta t}=\frac{\Delta i_{2}}{\Delta t}=\frac{E_{\mathrm{bat}, \mathrm{max}}}{L_{2}}
$$

since inductor $L_{1}$ is a filter inductor having no current ripple and thus the slope of current $i_{1}$ is zero. The amplification of the amplifier of the current loop is found with (12), (15), and (16):

$$
\begin{aligned}
A_{i} & =\frac{2 f_{s} V_{s}}{R_{s} \frac{\Delta i_{\text {in }}}{\Delta t}}=\frac{2 f_{s} V_{s} L_{2} G}{E_{\text {bat, } \max }} \\
& =\frac{210010^{3} 520010^{-6} 2.5}{105}=4.76
\end{aligned}
$$

where the peak-to-peak voltage of the sawtooth signal $V_{s}=5 \mathrm{~V}$. For high frequencies, the transfer function $H(s)$ is approximated by (6). The bandwidth $f_{\mathrm{bw}, i}$ of the current loop can be calculated from (6), (10), (11), and (17) as

$$
f_{\mathrm{bw}, i}=\frac{f_{s}}{\pi} \frac{V_{\mathrm{bus}}}{E_{\mathrm{bat}, \mathrm{max}}}=\frac{10010^{3} 120}{\pi 105}=36.4 \mathrm{kHz} .
$$

An integrator is added to the current amplifier to increase the gain for low frequencies.

Voltage Loop

The voltage loop has already been described at the beginning of this section and is shown in Fig. 6. The voltage loop gain $T_{v}$ is

$$
T_{\nu}(s)=\frac{K A_{\nu} G R}{1+s R C_{\text {bus }}} .
$$

The voltage amplification $K_{v}$ is

$$
K_{v}(s)=\frac{v_{\text {bus }}}{V_{\text {ref }}}=\frac{T_{v}(s)}{K\left(1+T_{v}(s)\right)}=\frac{A_{v} G R}{1+K A_{\nu} G R+s R C_{\text {bus }}} .
$$

Since $K A_{v} G R$ is usually larger than one, the term of one in (20) can be neglected. This results in

$$
K_{\nu}(s)=\frac{1 / K}{1+s \frac{C_{\text {bus }}}{K A_{\nu} G}} .
$$

The bandwidth of the voltage loop is

$$
f_{\mathrm{bw}, \nu}=\frac{K A_{\nu} G}{2 \pi C_{\mathrm{bus}}}
$$


From (21), it follows that the system behaves like a first-order system, provided that the transconductance $G_{i}(s)$ is constant and can be replaced by $G$. As (11) shows, this is not the case. To reduce the effect of the pole of the current loop, the bandwidth frequency of the voltage loop should be selected one decade lower than the bandwidth frequency of the current loop.

The input or bus impedance of the regulator is derived from Fig. 6 and (22) as

$$
Z_{b}=\frac{v_{\text {bus }}}{i_{c}+i_{\mathrm{in}}}=\frac{1}{s C_{\mathrm{bus}}+K A_{\nu} G}=\frac{1}{K A_{\nu} G} \frac{1}{1+\frac{s}{2 \pi f_{\mathrm{bw}, \nu}}} .
$$

This impedance should comply with the impedance mask given in Fig. 3. Therefore an integrator is added to the voltage amplifier. This results in a bus impedance of

$$
Z_{b}=\frac{1}{K A_{\nu} G} \frac{\frac{s}{2 \pi f_{z v}}}{\left(\frac{s}{2 \pi f_{z v}}+1\right)\left(\frac{s}{2 \pi f_{\mathrm{bw}, v}}+1\right)}
$$

where $f_{z \nu}$ is the frequency of the integrator zero.

Comparing (24) with the bus impedance mask shown in Fig. 3, it shows that the zero of the integrator must be higher than $100 \mathrm{~Hz}$, the bandwidth of the voltage loop lower than $10 \mathrm{kHz}$, and:

$$
\frac{1}{K A_{\nu} G} \leq Z_{b, \text { max }}
$$

This gives the minimum gain of the voltage amplifier as

$$
A_{v} \geq \frac{1}{K Z_{b, \max } G}
$$

The conductance $G$ is provided in Table I. The feedback factor $K$ depends on the reference voltage used. The reference voltage is usually created by a Zener diode. A Zener diode of $6.4 \mathrm{~V}$ is used. This gives

$$
K=\frac{V_{\text {ref }}}{V_{\text {bus }}}=\frac{6.4}{120}=0.053 \text {. }
$$

The minimum amplifier gain is then:

$$
A_{\nu}=\frac{1}{K Z_{b, \max } G}=\frac{1}{0.0530 .322 .5}=23.4 \text {. }
$$

The integrator in the voltage loop improves the static and dynamic response of the system. The steady state error is reduced to zero. The response will be faster for a smaller time constant or a higher frequency of the integrator zero. The frequency of the zero should be a decade lower than the bandwidth frequency of the voltage loop. The effect of the zero on the phase margin is then less than $6^{\circ}$. The minimum phase margin of the voltage loop is given by the design constraints as $60^{\circ}$. When the phase margin is larger, the response of the voltage loop can be made faster by

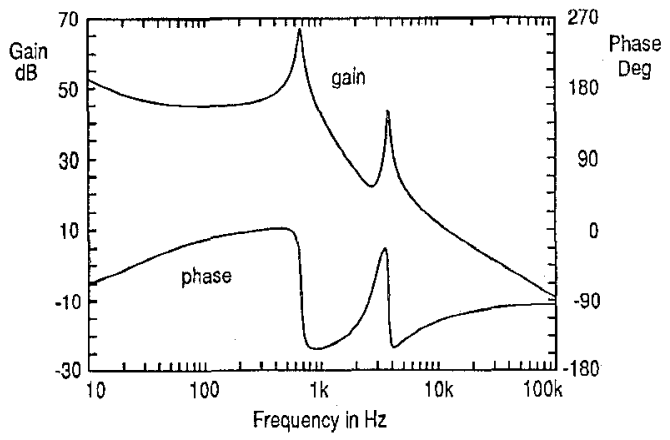

Fig. 9. Simulation of current loop gain $T_{i}$.

increasing the frequency of the integrator zero until the phase margin reaches $60^{\circ}$.

The bandwidth of the voltage loop is chosen a decade below the bandwidth of the current loop to make sure that the transconductance $G_{i}(s)$ can be considered ideal for the voltage loop. The bandwidth in combination with (18) is then:

$$
f_{\mathrm{bw}, v}=\frac{f_{\mathrm{bw}, i}}{10}=3.64 \mathrm{kHz}
$$

The bus capacitor is calculated from (22), (28), and (29) as

$$
C_{\mathrm{bus}}=\frac{K A_{\nu} G}{2 \pi f_{\mathrm{bw}, \nu}}=\frac{0.05323 .42 .5}{2 \pi 3.6410^{3}}=135 \mu \mathrm{F} .
$$

This value is a larger value than the minimum required as given in Table $\mathrm{I}$.

Filter inductor $L_{1}$ has no current ripple. Therefore its inductance cannot be easily determined as with inductor $L_{2}$. The value of the inductance is determined with the use of simulations [9]. Fig. 9 shows a simulation of the current loop gain. The peak in the loop gain at higher frequencies shifts to the right when the inductance of inductor $L_{1}$ is decreased. The inductance has been chosen such that this peak occurs at a frequency a decade below the bandwidth of the current loop, so that the phase margin of the current loop gain is not decreased by more than $5^{\circ}$. This resulted in $L_{1}=80 \mu \mathrm{F}$.

\section{EXPERIMENTAL RESULTS}

A breadboard of the novel topology including the complete PWM conductance control loop has been built. A metal-oxide semiconductor field effect transistor (MOSFET) of the type IRF 250 is used for the active switch. The passive switch consists of two 1N5826 diodes in series for reasons of redundancy. The solar array is simulated by a High Power Solar Array Simulator from Brentec/Eolas, with a maximum current capability of $10 \mathrm{~A}$. The battery is simulated by a High Power Battery Simulator also from Brentec/Eolas. It can either deliver or sink a maximum current of $20 \mathrm{~A}$ for a voltage between $30 \mathrm{~V}$ and $100 \mathrm{~V}$. The 


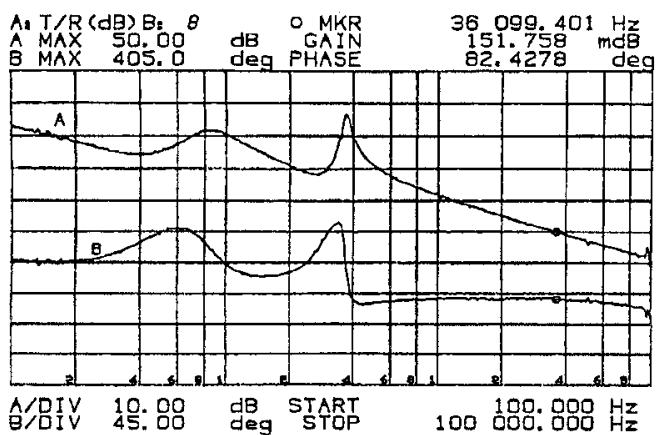

Fig. 10. Current loop gain $T_{i}$ without integrator $(100 \mathrm{~Hz} \ldots$ $100 \mathrm{kHz})$. Trace A: gain (10 dB/div). Trace B: phase $\left(45^{\circ} / \mathrm{div}\right)$.

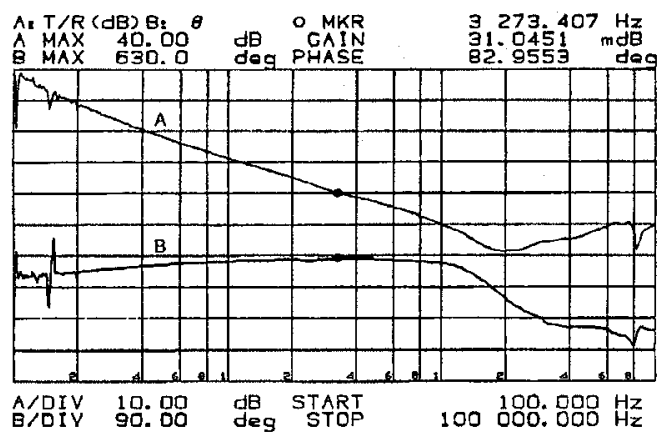

Fig. 11. Voltage loop gain $T_{\nu}(100 \mathrm{~Hz} \ldots 100 \mathrm{kHz})$. Trace A: gain $(10 \mathrm{~dB} / \mathrm{div})$. Trace B: phase $\left(90^{\circ} / \mathrm{div}\right)$.

bus load is simulated by a Hewlett Packard 6051A electronic load. The measurements are established under nominal conditions. The solar array simulator is set at its maximum of $10 \mathrm{~A}$. The electronic load is set at a resistance of $48 \Omega$, dissipating a current of $120 / 48=2.5 \mathrm{~A}$. The nominal input current is then $7.5 \mathrm{~A}$.

The bus ripple voltage was measured to be below $10 \mathrm{mV}$, much lower than specified in Table I. The peak-to-peak spike voltage due to the switching was measured to be around $1 \mathrm{~V}$.

The current and voltage loop gains are measured with a Hewlett Packard 4194A impedance/gain-phase analyzer. They are shown in Figs. 10 and 11.

The current loop response is measured without the integrator at the current amplifier $A_{i}$. It appears to be very difficult to measure it with the integrator. The bandwidth of the current loop is the same as the cross-over or $0 \mathrm{~dB}$ frequency of the open current loop. The marker in Fig. 10, shows that the bandwidth is $36.1 \mathrm{kHz}$, which is close to the calculated value of (18). The phase margin is $82.4^{\circ}$.

The voltage loop response in Fig. 11 is measured with the integrators at both the current and the voltage amplifier. The bandwidth is $3.3 \mathrm{kHz}$, which is lower than the value resulting from (29). The phase margin is $82^{\circ}$, ensuring a stable first-order control.

The bus impedance is measured by applying a sine modulation of $\mathbb{1} \mathrm{A}$ to the load current. The measured impedance is shown in Fig. 12. The impedance mask

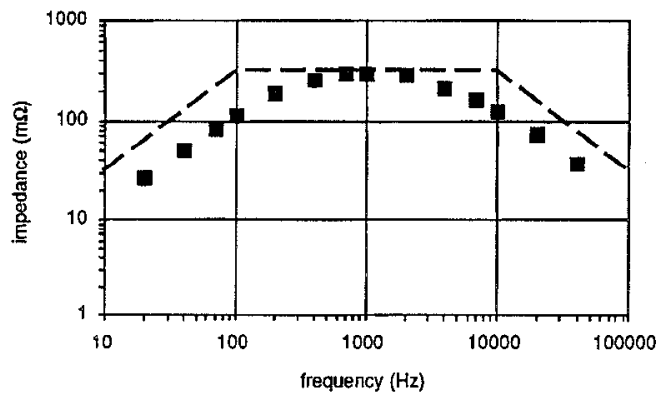

- measurements - - -impedance mask

Fig. 12. Measured bus impedance.

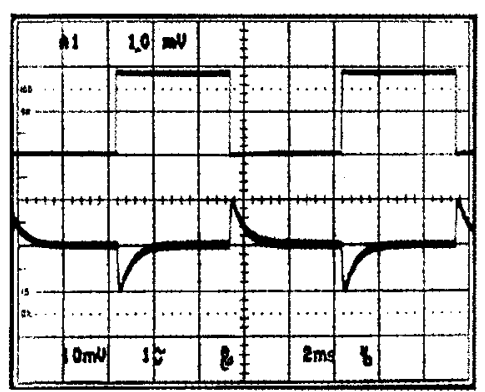

Fig. 13. Measured transient response of bus voltage (time: $2 \mathrm{~ms} / \mathrm{div})$. Upper trace: load current ( $2 \mathrm{~A} / \mathrm{div})$. Lower trace: bus voltage $(1 \mathrm{~V} / \mathrm{div})$.

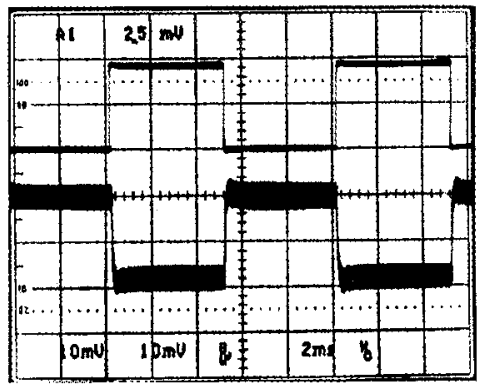

Fig. 14. Measured transient response of input current (time: $2 \mathrm{~ms} / \mathrm{div}$ ). Upper trace: load current (2 A/div). Lower trace: input current $(1 \mathrm{~V} / \mathrm{div})$.

shown in Fig. 3 is also indicated in Fig. 12. The bus impedance of the regulator stays below the impedance mask. The maximum measured impedance is $310 \mathrm{~m} \Omega$.

The responses of some transients in the time domain are shown in Figs. 13 and 14. A 50\% current modulation $(3.75 \mathrm{~A})$ is applied at the load current with a frequency of $100 \mathrm{~Hz}$. Fig. 13 shows the response of the bus voltage and Fig. 14 shows the response of the input current. The bus voltage variation is $1 \mathrm{~V}$, which is less than $1 \%$ of the bus voltage $(1.2 \mathrm{~V})$. The responses demonstrate the first-order behavior of the control.

The efficiency of the converter has been measured and is shown in Fig. 15. The efficiency of the converter is higher than the required efficiency of 


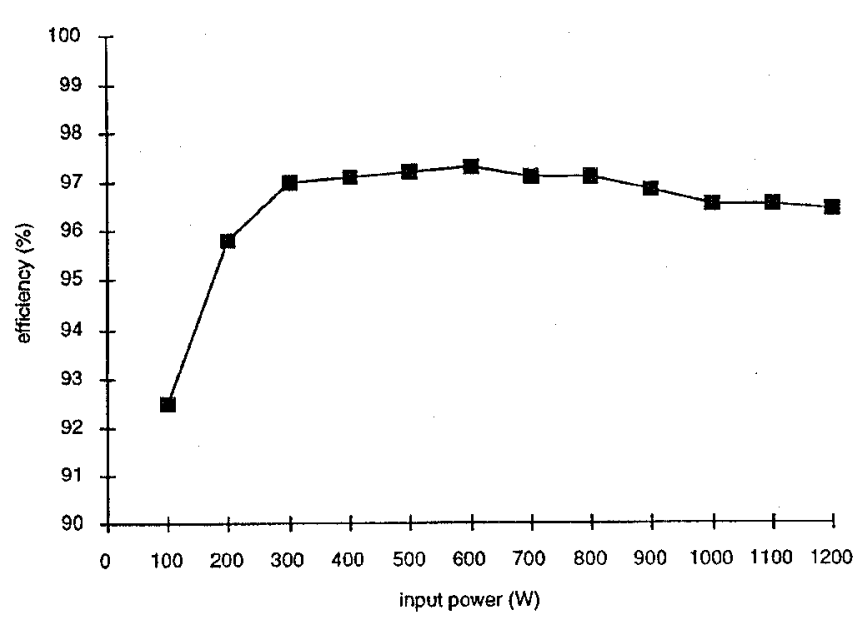

Fig. 15. Measured efficiency.

92\%. No snubber circuits for the switches and no additional damping circuits have been used. The power dissipation of the control circuitry has not been taken into account either. The power consumption of the control circuitry is less than $3 \mathrm{~W}$.

\section{CONCLUSIONS}

A BCR has been designed and built for the Columbus MTFF power system. Because this application has the unusual feature of input conductance control, a conventional buck converter with an input filter as shown in Fig. 4, could not be used. This resulted in a unstable current loop. A study was made to find an alternative suitable topology which is shown in Fig. 5. This topology is an elementary modification of the buck converter with input filter where the filter inductor is relocated to the return or ground line. PWM conductance control can be applied at the input of the converter. The current loop is stable and the overall behavior of this converter is of the first order.

\section{REFERENCES}

[1] Duivenbode, J., and Capel, A. (1989)

The Columbus power system simulation programme. In Proceedings of the European Space Power Conference, ESA SP-294 (1989), 53-60.

[2] Leisten, V., and Koss, M. (1989)

$120 \mathrm{~V}$ test bed for the Columbus power system. In Proceedings of the European Space Power Conference, ESA SP-294 (1989), 5-12.

[3] Schreger, A. (1991) Computer simulation of the Columbus 4-domain $120 \mathrm{VDC}$ mainbus regulation.

In Proceedings of the European Space Power Conference, ESA SP-320 (1991), 239-244.

[4] O'Sullivan, D. M., et al. (1988)

PWM conductance control. In Proceedings of the IEEE Power Electronics Specialists Conference, 1988, 351-359.

[5] van Dijk, E., et al. (1993) A novel topology for the battery charger of the Columbus MTFF power sub-system. Proceedings of the European Space Power Conference, ESA WPP-054 (1993), 289-294.

[6] Spruijt, H. J. N., et al. (1991)

ESA power standard. Proceedings of the European Space Power Conference, ESA SP-320 (1991), 145-150.

[7] Meerman, E. R. W., and Spruijt, H. J. N. (1989) PWM converter topologies. In Proceedings of the European Space Power Conference, ESA SP-294 (1989), 297-305.

[8] Tymerski, R., and Vorpérian, V. (1988) Generation and classification of PWM dc-to-dc converters. IEEE Transactions on Aerospace and Electronic Systems, 24, 6 (Nov. 1988), 743-754.

[9] van Dijk, E., Spruijt, H. J. N., O'Sullivan, D. M., and Klaassens, J. B.

PWM-switch modeling of dc-dc converters. IEEE Transactions on Power Electronics, 30, 6 (Nov. 1995), 659-665. 

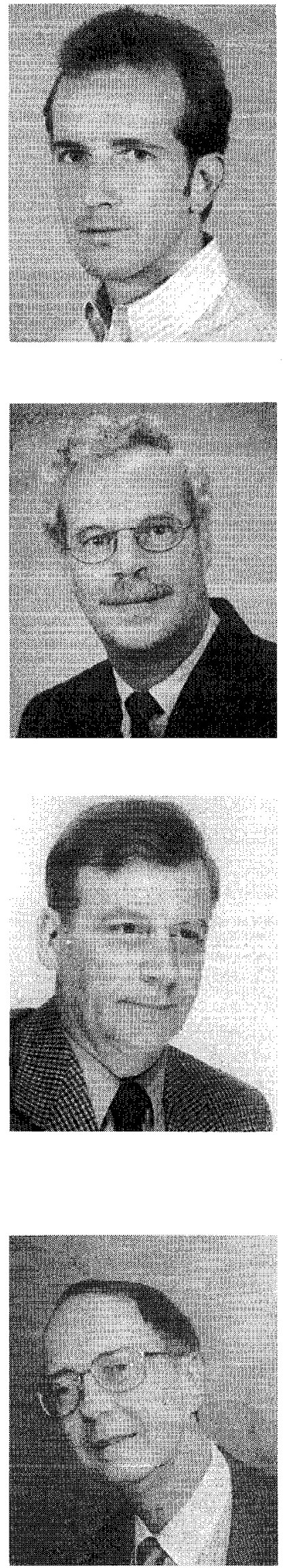

Edwin van Dijk was born in Oud-Beijerland, The Netherlands, in 1968. He received his M.Sc. degree in electrical engineering from the Delft University of Technology, Delft, The Netherlands, in 1992.

During his study in 1991 and 1992, he worked on the modeling and the application of dc-dc converter topologies in space power systems at the Power and Energy Conversion Division of the European Space Research and Technology Centre (ESTEC), Noordwijk, The Netherlands. Since 1992, he is working as a Ph.D. student at the Laboratory for Power Electronics and Electrical Machines of the Delft University of Technology.

Herman Spruijt was born in Wassenaar, The Netherlands in 1940.

He has worked at the European Space Agency in Noordwijk, The Netherlands since 1966. The first 6 years as a satellite project engineer dealing with the HEOS-1, HEOS-2, GEOS-1 and GEOS-2 scientific satellites. The last 23 years as a power subsystem engineer in the Power \& Energy Conversion Division. He is presently involved in the support of the ESA moon program.

He is the holder of two ESA patents. One on the battery charge termination using the TDT (temperature derivative termination). The other one on 16 new $\mathrm{dc} / \mathrm{dc}$ PWM converter topologies.

Dermot O'Sullivan was born on May 13, 1943, in Dublin, Ireland. He received the B.E. degree in electrical engineering from the University College, Dublin, in 1965.

In 1965, he joined Hawker Siddeley Dynamics as a Power System Engineer. From 1969 to the present, he has been a member of the European Space Agency in the Technical Centre (ESTEC) of Noordwijk, The Netherlands. He is presently Head of the Power and Energy Conversion Division and has applied for several patents in this area.

J. Ben Klaassens was born in Assen, The Netherlands in 1942. He received his B.S., M.S., and Ph.D. degrees in electrical engineering from the Delft University of Technology in The Netherlands, where he is currently Associate Professor.

His work has been concerned with inverter circuits, pulsewidth modulation, and the control of electrical machinery. His research work and professional publications are in the area of converter systems with high internal pulse frequencies for sub-megawatt power levels employing thyristors, power transistors and IGBTs. His current interest is in the area of control of converters and electrical drives.

Dr. Klaassens has published a variety of papers on series-resonant converters for low and high power applications. He has designed and built prototypes of the early dc-dc to the recent ac-ac series-resonant converters for a wide variety of applications such as electric motors and generators, communication power supplies, radar signal generators, arc welders, and space applications. 